\title{
EDUCAÇÃO AMBIENTAL PARA GESTÃO SUUSTENTÁVEL EM MEIOS DE HOSPEDAGEM DO LITORAL NORTE DA PARAÍBA
}

\author{
Pedro Henrique Cesar ${ }^{1}$ \\ Daniel Durante Pereira Alves ${ }^{2}$ \\ Joel Silva dos Santos ${ }^{3}$ \\ Sueli Aparecida Moreira ${ }^{4}$
}

Resumo: O tema sustentabilidade surge em contrapartida à crise ambiental decorrente do modelo econômico predatório. O turismo e a hospitalidade são segmentos que requerem uma perspectiva sustentável, pois se apropriam de espaços de frágil equilíbrio ambiental, impactando a relação entre sociedade e meio ambiente. O presente ensaio retrata um conjunto de intervenções em meios de hospedagem localizados no litoral norte da Paraíba. Ações sobre conceitos e práticas sustentáveis foram dirigidas ao pessoal de hospitalidade. $\mathrm{O}$ aspecto mais vulnerável trata-se da capacitação de recursos humanos. Ações de educação ambiental poderão contribuir para a conservação da região litorânea paraibana para que seja apreciada, mas não explorada.

Palavras-chave: Hospitalidade; Pesquisa-Intervenção; Gestão Sustentável; Educação Ambiental.

Universidade Federal de Campina Grande. E-mail: pedrohcesar@hotmail.com

2 Universidade Federal do Rio Grande do Norte. E-mail: durante@ufrnet.com

3 Universidade Federal da Paraíba. E-mail: joealgrafia.santos@gmail.com

${ }^{4}$ Universidade Federal do Rio Grande do Norte. E-mail: suelimoreira@yahoo.com.br

Revbea, São Paulo, V. 13, No 2: 396-416, 2018. 


\section{Introdução}

Devido ao modelo econômico dominante, a sociedade contemporânea passa por uma crise socioambiental sem precedentes. A situação atual encontrase em um nível tão avançado de degradação que a continuidade da forma como habitamos a terra, nosso modo de produzir, de distribuir e de consumir nos últimos séculos comprometerá a nossa qualidade de vida; portanto, imperiosamente, impõe-se um novo começo, com novos conceitos, novas percepções. Trata-se, sem mais nem menos, de refundar o pacto social entre os humanos e a natureza (BOFF, 2014, p.15).

O compromisso ético com a natureza demanda um novo modelo de desenvolvimento com limites e referências mais sustentáveis. A crise atual é resultado de um tipo de desenvolvimento pautado por um sistema econômico que prioriza o lucro frente à natureza e a sociedade. No enfrentamento dessas circunstâncias, faz-se necessário buscar novas alternativas ao desenvolvimento. De acordo com Porto-Gonçalves (2015, p.66) o próprio conceito de desenvolvimento não contempla o desafio ambiental.

Veiga (2012, p. 87) ao questionar a veracidade de um desenvolvimento ambientalmente sustentável afirma que tal conceito é o carro-chefe de um processo de institucionalização que deve inserir o meio ambiente na agenda política internacional, além de fazer com que essa dimensão passe a permear a formulação e a implantação de políticas públicas em todos os níveis nos Estados nacionais e nos órgãos multilaterais e de caráter supranacional. Para Boff (2014, p. 16) sustentabilidade é também um modo de ser e de viver que exige harmonizar as práticas humanas às potencialidades limitadas de cada bioma $\mathrm{e}$ às necessidades das presentes e das futuras gerações.

A contradição do conceito de sustentabilidade em um mundo com recursos finitos, mas que ao mesmo tempo se utiliza de um sistema econômico que busca o lucro infinito, nos força a buscar alternativas que minimizem o ruído entre os desenvolvimentos econômico e socioambiental. Sachs $(2009$, p. 35) diz que a sustentabilidade é, evidentemente, incompatível com a percepção sem restrições do mercado.

Portanto, o conceito de sustentabilidade nos convida à supressão do pensamento econocêntrico (PORTO-GONÇALVES, 2012), cujo processo de desenvolvimento, além da perspectiva econômica, envolve as questões da sociedade, como territorialidade, a política, a cultura e a natureza.

Para Nader (2002, p. 43) "a noção de sustentabilidade nos abriu o campo conceitual para avaliarmos a abrangência do tratamento dos limites de sustentação no entre jogo do sistema econômico e o funcionamento dos ecossistemas". Esse tipo de desenvolvimento compromete várias vertentes e todas têm de se desenvolver da mesma forma em uma unidade que contém várias outras unidades, assim a sustentabilidade é, antes de tudo, complexa. Morin (1977, p. 141) afirma que: 
A complexidade surge no seio do uno ao mesmo tempo como relatividade, relacionalidade, diversidade, alteridade, duplicidade, ambiguidade, incerteza, antagonismo, e na união destas noções que são, umas em relação às outras, complementares, concorrentes e antagônicas. O sistema é o ser complexo que é superior, inferior, distinto de si mesmo. É, ao mesmo tempo, aberto e fechado.

O fato é que vivemos em um sistema econômico que observa a natureza como dádiva e que, com isso, não a internaliza nas suas contabilidades. PortoGonçalves (2015, p.31) afirma que o capitalismo, pela natureza de sua própria história, é fossilista. Assim, observamos a complexidade que é a sustentabilidade, visando uma mudança de paradigma onde devemos superar a nossa racionalidade econômica e partirmos para uma racionalidade ambiental (LEFF, 2011).

Nesse sentido, a sustentabilidade surge como um componente ético na nossa sociedade na busca por uma sinergia das atividades antrópicas com as ambientais. Essa ética deve ser buscada em todos os níveis e componentes da sociedade inclusive na hospitalidade que fundamenta a atividade do turismo.

O turismo tem um importante significado espacial, social e econômico para as sociedades modernas. Ao contrário do pensamento ortodoxo do capital, essa atividade tem o ambiente como matéria prima e vem se expandido rapidamente e de forma, muitas vezes, plural, com turismo solidário, participativo, comunitário, de inclusão, reproduzindo uma contradição intrínseca à produção capitalista. $O$ turismo ainda se diferencia do pensamento hegemônico do capital com algumas propostas políticas de turismo que elege outras prioridades como o bem-estar social das comunidades acima da acumulação de lucro (CORIOLANO, 2014).

Em termos de impactos na sociedade podemos afirmar que o turismo é ambivalente pois, ao mesmo tempo em que ele oferece um leque de oportunidades de bem-estar social ao possibilitar inúmeras atividades de lazer, de intercâmbio cultural e desenvolvimento econômico, também pode transformar-se em atividade de risco, produzindo efeitos indesejáveis à natureza, à cultura local e às atividades econômicas tradicionais (FARIAS; DIAS, 2011, p. 29).

Como atividade econômica, se apropria dos ambientes naturais na intenção de transformá-lo em espaço de lazer e consumo, resultando em impactos positivos e negativos (DIAS, 2002; CORIOLANO, 2014;). Para Rushman (2000, p. 15) a inter-relação entre o turismo e o meio ambiente é incontestável, uma vez que este último constitui a "matéria-prima" da atividade. O contato com a natureza é, atualmente, uma das maiores motivações das viagens de lazer. Grimm e Sampaio (2011) afirmam que a atividade turística está intimamente ligada às características e às condições socioambientais e qualquer problema neste âmbito acarretará, sem dúvidas, em impactos negativos, 
descaracterizando o âmago dessa atividade que deve primar pela qualidade ambiental e conservação das características culturais do local.

O mito da natureza intocada (DIEGUES, 2001) pode ter impulsionado o turismo na busca por paisagens, muitas vezes em ambientes complexos, cujo planejamento não se atentou para a fiscalização e controle da capacidade de carga e tampouco emancipou a comunidade no papel da governança a fim de mitigar impactos e sensibilizar o processo de desenvolvimento da atividade sob parâmetros sustentáveis.

A indústria hoteleira vem demonstrando interesse na adequação às questões da sustentabilidade nos locais onde estão inseridos os empreendimentos. O cenário de biodiversidade do seu entorno agrega valor a suas atividades, impactando os ecossistemas onde estão inseridos. Coriolano (2009) responsabiliza a hospitalidade como a atividade mais impactante do turismo devido à exigência da apropriação de espaços, demarcação de territórios e centralização de serviços. Muitos meios de hospedagem estão localizados em áreas de beleza cênica, cidades históricas ou em regiões de delicado equilíbrio ambiental. Gonçalves (2004) afirma que a localização das operações dos hotéis é definida em função do mercado e modifica toda a dinâmica do meio ambiente onde se insere.

As atividades hospitaleiras têm uma grande dependência da natureza, tanto para efeitos de manutenção dos serviços como de atração, Bohdanowicz (2005) corrobora ao dizer que o desenvolvimento e bem-estar da indústria hoteleira nos destinos turísticos depende da constante disponibilidade de recursos naturais e também do apelo natural que é determinante para levar os turistas a esses destinos.

Nesse sentido, é importante que os meios de hospedagem, tanto no planejamento quanto na operação dos seus serviços, internalizem questões socioambientais. A gestão ambiental é uma estratégia para auxiliar a gestão no alcance dos seus objetivos socioambientais. De acordo com a Academia Pearson (2011, p. 97) a gestão ambiental pode ser definida como o braço que busca reduzir o impacto das atividades econômicas sobre a natureza. Ela deve estar presente em todos os projetos de uma organização, desde seu planejamento e execução até sua completa desativação.

Durante meio século, o Brasil, que fundamentou sua economia em um sistema econômico agrário, cujos empreendimentos visavam apenas à lucratividade, passou a ter responsabilidade e obrigações perante os acionistas e, ainda que de modo insipiente, iniciou um discurso de responsabilidade pelos impactos socioambientais decorrentes das atividades de turismo. Esse movimento de preservação e conservação ambiental também é resultado de protocolos internacionais dos quais o Brasil é signatário e, principalmente, da pressão do hemisfério norte em direção ao comportamento desenfreado do Brasil, que detém uma das maiores biodiversidades do mundo e, ao mesmo tempo, tornou-se o celeiro do mundo. 
As organizações não podem ficar à margem dos problemas e desafios enfrentados pela sociedade, em particular no que concerne à marginalização e desigualdade sociais e subtração da biodiversidade decorrentes da racionalidade econômica na qual estão inseridas, sendo que a sua responsabilidade vai para além do cumprimento das leis e normas que regulamentam os negócios, ou seja, uma responsabilidade socioambiental (FIGUEIRA; DIAS, 2011, p. 51). Apesar de o conceito, muitas vezes, ser utilizado de forma equivocada ou como uma promoção mercadológica, ainda é válido como iniciativa.

Contudo, a gestão sustentável surge da ânsia de um mundo equilibrado e, para que esse modelo de sociedade seja implantado na sociedade pósmoderna, torna-se necessário não apenas que grupos sociais ou organizacionais incorporarem essa concepção isoladamente, mas que a humanidade, como um todo, reavalie suas práticas, princípios e necessidades. Precisamos enfrentar o principal de todos os entraves a um futuro mais promissor: nós mesmos (CAMARGO, 2003, p. 123).

A região do litoral norte da Paraíba é conhecida pelas suas riquezas naturais e por seu rico patrimônio histórico e cultural. Essa região apresenta uma diversidade biológica e cultural muito singular, onde se inserem o maior número de unidades de conservação do estado; além de contar com uma cultura étnica muito rica, representada pela presença da etnia Potiguara. A região é alvo dos turistas que pretendem contemplar a beleza cênica da região e compreender a cultura local. A área conta com um fluxo turístico razoável que ocorre sazonalmente (CESAR, 2016). De acordo com Barbosa-Segundo (2015), o turismo praticado na região é desprovido de um planejamento estratégico que leve em consideração os princípios de uma gestão sustentável.

A ausência de uma política ambiental para os meios de hospedagem e a falta de conhecimento específico em relação às questões ambientais são lacunas que comprometem a qualidade dos serviços e contribuem para geração de impactos socioambientais na região (CESAR, 2013). De acordo com Menezes et. al. (2011) as pessoas que trabalham no ramo da hospitalidade na região, em sua maioria, são desprovidas de cursos de capacitação. Em acordo à literatura, os achados evidenciam uma demanda crescente na capacitação de recursos humanos e de políticas públicas que estabeleçam parâmetros para os negócios turísticos e de hospedagens, principalmente aqueles de pequeno porte, no contexto de áreas protegidas.

Veiga $(2014$, p. 17) nos alerta que o caminho para a sustentabilidade se encontra na cooperação e em ações locais e policêntricas. Buarque (1999, p. 30) diz que a sustentabilidade deve forçar uma "solidariedade" entre os povos, na medida em que as formas insustentáveis de agressão ao meio ambiente contribuem para a degradação da natureza de cada local, o que leva à busca de um desenvolvimento local sustentável. O caminho para a sustentabilidade no turismo pode envolver o turismo de base comunitária. De acordo com Coriolano (2009, p.282) "o turismo comunitário é aquele em que as comunidades de forma 
associativa organizam arranjos produtivos locais, possuindo o controle efetivo das terras e das atividades econômicas associadas à exploração do turismo".

Considerando as dificuldades dos estabelecimentos e as supostas incongruências entre cultura organizacional e questões ambientais, elaborou-se o presente estudo com o objetivo de desenvolver ações interventivas junto aos meios de hospedagem do litoral norte da Paraíba, com a finalidade de auxiliar na sensibilização ambiental e, consequentemente, na adoção de práticas sustentáveis nas operações de seus serviços.

\section{Metodologia}

\section{Área de Estudo}

O litoral norte Paraibano é uma região com características muito singulares. Além de ser uma área com aspectos ainda "intocáveis" pelo desenvolvimento predatório tem um rico patrimônio histórico e cultural. A região é composta por cinco municípios: Lucena, Rio Tinto, Marcação, Baía da Traição e Mataraca. Com exceção de Lucena, todos os outros municípios detêm uma representatividade muito forte da etnia Potiguara. A presença dos Potiguaras revela os aspectos ainda preservados dessa região.

Em Rio Tinto existe o processo de tombamento do conjunto arquitetônico que foi retomado em 2012, após anos sem avanço, com a execução do Projeto "Estudos para instrução de tombamento da Igreja de São Miguel, Baía Traição e Rio Tinto-PB". Outro bem cultural existente em Rio Tinto é a Igreja de Nossa Senhora dos Prazeres de Monte-Mor, protegido por meio do Decreto oㅜ 31.841, de 03 de dezembro de 2010. No município de Lucena, no ano de 1949, a Igreja de Nossa Senhora da Guia foi tombada pelo IPHAN (Figura 69), uma referência barroca edificada pelos frades carmelitas que chegaram à Paraíba em 1561, com o objetivo de catequizar os indígenas da região (PIZZOL, 2006). Essa igreja, juntamente com a Fortaleza de Santa Catarina, as ruínas de Almagre e a atalaia de Forte Velho, compõem o Sistema Religioso-Defensivo da Capitania da Paraíba (ICMBio, 2014, p. 166). A área é a que mais agrega Unidades de Conservação (UC) do Estado (ICMBio, 2014) divididas entre as três esferas: municipal, estadual e federal. Entre essas UC estão as Áreas de Preservação Ambiental (APA); Reserva Biológica (REBio); Área de Relevante Interesse Ecológico (ARIE), além das reservas indígenas. Esse fato mostra o diferencial ambiental da região pesquisada que se situa entre os municípios de Lucena e Mataraca, englobando, ainda, Rio Tinto, Baía da Traição e Marcação, que juntos formam uma extensão de aproximadamente $40 \mathrm{~km}$ de zona costeira, configurando-se em um ecossistema que é considerado como muito suscetível a impactos.

O litoral norte da Paraíba tem um grande potencial para 0 desenvolvimento da prática do ecoturismo. No entanto, a atividade na região é desprovida de um planejamento adequado, o que resulta em impactos socioambientais preocupantes (BARBOSA-SEGUNDO, 2015). Umas das consequências da inexistência de um planejamento turístico responsável é a 
ausência de práticas que visem ações socioambientais por parte dos meios de hospedagem local.

As consequências da inexistência de um planejamento turístico adequado na região são refletidas até mesmo no plano de manejo da Área de Proteção Ambiental (APA) do Rio Mamanguape. No documento consta que "é permitida a construção de empreendimentos turísticos ou outras atividades de grande porte, desde que atenda as condicionantes do processo de licenciamento ambiental, tratando-se, obrigatoriamente, dos projetos de saneamento de esgoto" (ICMBio, 2014, p. 267). Equipamentos e empreendimentos turísticos de grande porte podem resultar em grandes impactos. Coriolano (2011, p.7) corrobora afirmando que o turismo tem se revelado, com raras exceções, predatório dos ecossistemas naturais, resultado da implantação de infraestruturas pesadas e inadequadas, megaempreendimentos, especulação imobiliária, o que tem contribuído para agressão à natureza.

Tal perspectiva do plano de manejo da unidade de conservação (ICMBio, 2014) se apresenta de forma equivocada e dando espaço para que organizações de grande porte possam se apropriar de amplas áreas, impondo uma lógica de mercado que não se enquadra nos preceitos de um turismo desenvolvido em áreas protegidas, o ecoturismo. Para Dias (2003, p. 107) esse tipo de turismo de ser praticado em pequenos grupos que não deixem indícios de terem visitado uma área. Devem procurar compreender as relações existentes nos ecossistemas, respeitá-las e mantê-las intactas e em harmonia com as populações locais. O ecoturismo pode ser entendido como o turismo sustentável praticado em áreas naturais.

A Lei $n^{\circ} 9.985$ que institui o Sistema Nacional de Unidades de Conservação (SNUC) no seu art. $5^{\circ}$ menciona como um dos seus objetivos "favorecer a recreação com o contato com a natureza e o turismo ecológico".

Diegues (2001) adverte que os problemas acarretados pelo turismo em Unidades de Conservação agravam-se quando a atividade desassocia-se da vontade da população tradicional, vista como um atrativo ou produto turístico.

Contudo, é importante que o turismo desenvolvido em ambiente paradisíaco tenha como ponto de partida um planejamento turístico sob gestão pública eficiente e sob efetiva interlocução com representantes da comunidade, para reivindicar mais qualidade de vida e acesso aos direitos sociais locais.

\section{Método}

Trata-se de dados de pesquisa realizada em dezessete meios de hospedagem distribuídos entres os cinco municípios correspondentes à região do litoral norte da Paraíba. Utilizou-se como referência ou ponto de partida o projeto Gestão Ambiental e Sustentabilidade: uma avaliação da responsabilidade socioambiental dos meios de hospedagem situados no litoral norte da Paraíba, que teve como foco elucidar a relação e percepção dos gestores dos meios de hospedagem com uma gestão sustentável. O projeto 
concluiu que os empreendimentos não estavam em conformidade com uma gestão sustentável (CESAR et. al., 2016).

Em face da demanda notada, o desenvolvimento das ações do presente estudo compreendeu as seguintes etapas: identificou-se, primeiramente, a situação operacional e a relação dos meios de hospedagem da região com o meio ambiente. Previamente dedicou-se a observar se a cultura organizacional dos meios de hospedagem da região pesquisada enfatizava questões ambientais.

Como instrumento de coleta de dados foi utilizado um roteiro de entrevista semiestruturada que levou em consideração as práticas dos meios de hospedagem relacionadas à responsabilidade socioambiental; práticas de gestão ambiental como economia de água e energia; e política dos resíduos sólidos.

Os resultados encontrados por Cesar et al. (2016) foram importantes para o diagnostico da relação dos meios de hospedagem frente à gestão sustentável e também para estabelecer os limites e os temas das intervenções que seriam desenvolvidas e aplicadas junto aos participantes da pesquisa-ação.

Do ponto de vista metodológico, foi considerada a perspectiva de Haguette (1995, p. 112) de que a pesquisa-ação visa desenvolver planos de ação, ou seja, o pesquisador entra em uma situação existente, estabelece o diagnóstico e propõe medidas para sanar o problema. Pouparte (2008, p. 131) acrescenta que a pesquisa-ação tem por objetivo aprofundar o conhecimento compreensivo de um problema no intuito de orientar a ação para solucionar tal problema. Para Thiollent (1986, p. 14):

A pesquisa-ação é um tipo de pesquisa social com base empírica que é concebida e realizada em estreita associação com uma ação ou com a resolução de um problema coletivo e no qual os pesquisadores e os participantes representativos da situação ou do problema estão envolvidos de modo cooperativo ou participativo.

Assim, desenvolveu-se a proposta de intervenção junto aos administradores e funcionários dos empreendimentos pesquisados, através de entrevistas e diálogos informais, a fim de sensibilizar para uma consciência inicial sobre a relação de suas atividades com a natureza. Buscou-se elucidar, através de um modo teórico as práticas turísticas e hospitaleiras, seus conceitos, sua importância, seus impactos positivos e negativos, sempre relacionando as propostas ao meio ambiente. As ações desenvolvidas almejavam a sensibilização das pessoas envolvidas com meios de hospedagem na região para com uma gestão sustentável, mostrando a importância da incorporação de aspectos ambientais na respectiva gestão, buscando ajustar suas práticas a um modelo de gestão que mitigasse sérios impactos. Thiollent (1986, p. 18), diz que, nesse caso, não se trata apenas de resolver um problema imediato e sim 
desenvolver a consciência da coletividade nos planos político ou cultural, a respeito dos problemas importantes que enfrenta, mesmo quando não se vêem soluções a curto prazo. O objetivo passa a tornar-se mais claro aos olhos dos participantes quando a natureza e a complexidade dos problemas ambientais entram em pauta no horizonte das reflexões.

Todas as propostas foram formuladas levando em consideração a realidade dos empreendimentos, pois a maioria dos meios de hospedagem situados no litoral norte da Paraíba era de pequeno ou médio porte. Assim, as ações foram desenvolvidas através de métodos alternativos, relativamente econômicos e de fácil execução.

Finalmente realizou-se a intervenção de maneira atenta aos detalhes apontados por Chiazzotti (2006), de que a pesquisa-ação em organizações é um percurso longo que logo no inicio deve analisar as condições de exequibilidade, as negociações prévias até um plano provisório de pesquisa; na fase de execução ela exige a definição clara do que se quer resolver, a gestão da participação, a recolha dos dados, a proposição da solução, a execução e avaliação; e na fase de encerramento, o acompanhamento duradouro das ações propostas para que a pesquisa não se esgote nas conclusões formais de um texto ou relatório.

\section{Resultados e Discussão}

\section{Diagnóstico}

Durante a primeira etapa do projeto de pesquisa notou-se uma grande dificuldade dos meios de hospedagem da região do litoral norte da Paraíba de funcionarem adequando-se a uma gestão sustentável. Observou-se que os empreendimentos apresentavam pouca ou nenhuma conformidade com uma gestão sustentável. Durante a análise, constatou-se que suas práticas em respeito ao meio ambiente eram estritas à economia de água, energia, política dos resíduos sólidos. Portanto, a gestão ambiental e socioambiental não encontravam respaldos em nenhuma política ambiental.

No primeiro momento da pesquisa identificou-se que a administração dos empreendimentos e os recursos humanos estavam longe de um entendimento amplo e necessário sobre o conceito de sustentabilidade e sobre a sua importância na gestão dos meios de hospedagem. Esse cenário se elucida no momento da pesquisa em que os proprietários são indagados sobre as respectivas percepções mediante o termo sustentabilidade. Constatou-se uma frequente falta de conhecimento por parte da maioria deles, uma vez que apenas um entrevistado soube responder. $\mathrm{O}$ fato do desconhecimento pode se refletir na ausência de práticas promotoras da sustentabilidade na região.

A pesquisa-ação abrangeu a intervenção em dezessete meios de hospedagem. Posterior ao diagnóstico buscou-se, junto aos proprietários dos meios de hospedagens, métodos que visassem a inserção da questão ambiental no cotidiano da administração dos empreendimentos hospitaleiros da região 
pesquisada, levando em consideração a sua realidade. Em posse da informação de que a implementação de um sistema de gestão ambiental é custosa e delicada (SEIFFER, 2009; ACADEMIA PERSON, 2011; DIAS, 2011) e demanda todo um aporte tecnológico, tempo e outros fatores que cabem ao planejamento estratégico, iniciou-se a etapa de intervenção.

O perfil dos meios de hospedagens corresponde ao de pequeno porte. Com exceção de um hotel, todos os outros se classificavam como pousadas. $O$ pequeno porte dos meios de hospedagem se caracteriza como um aspecto positivo, pois indica que a atividade tem alguns princípios de base comunitária.

Coriolano (2009) corrobora afirmando que:

A atividade turística além de construir espaços simbólicos, tece rede extensa de pequenos negócios que, por sua vez, cria sociabilidades as mais diversas. Assim, seguem pari passu os dois eixos do turismo: o globalizado e o de base comunitária, que em efervescência se contrapõem e se complementam, e este segmento, muitos governos não conseguem apreender.

Certificou-se dos limites impostos e a realidade dos empreendimentos e, então, os envolvidos - pesquisadores, funcionários e proprietários - pensaram ações que pudessem auxiliar na inserção do conceito de sustentabilidade aos indivíduos que atuam no ramo hospitaleiro no litoral norte paraibano. Veiga (2014) recomenda que para buscar a sustentabilidade seja preciso ações policêntricas para alcançar benefícios em várias escalas. E é nessa perspectiva que esse estudo de intervenção se insere.

Após apresentar a proposta aos participantes da pesquisa, foram elencadas ações em conjunto, que resultaram em três propostas: minicursos; uma cartilha e a apresentação do guia de implementação do sistema de gestão ambiental NBR 15401, desenvolvido através de uma parceria entre o SEBRAE e a ABNT que possibilitou a distribuição de apostilas de cunho técnico elaborada pelo SEBRAE e ABNT, intitulada: Meios de hospedagem - sistema de gestão da sustentabilidade.

\section{Minicursos}

$\mathrm{Na}$ etapa do diagnóstico concluiu-se que os empreendimentos pesquisados se destacavam quando o assunto se referia à priorização da população nativa na formação do quadro de funcionários. Todos os gestores responsáveis pelo quadro de funcionários afirmaram privilegiar a contratação de pessoas da região. Podemos observar no relato da entrevistada de nome ficcional Izabel $(56)^{4}$, que possui um meio de hospedagem dentro dos limites da

\footnotetext{
${ }^{4}$ Os nomes dos entrevistados expostos durante todo o texto são ficcionais.
}

Revbea, São Paulo, V. 13, № 2: 396-416 2018.

revista brasileira

educação ambiental 
APA do Rio Mamanguape, quando indagada sobre essa questão afirma: "Sim, sempre daqui da redondeza!" Assim também, o entrevistado Diogo (34) nativo e responsável pela administração do meio de hospedagem na qual trabalha, em seu relato, afirma que "Sim, no momento todos os funcionários são daqui da região, inclusive eu". O entrevistado Romário (22) que é estudante do curso de engenharia ambiental e trabalha no ramo da hospitalidade há apenas dois anos, relata: "Com certeza, sempre foi da comunidade." Esse fato vai ao encontro do pensamento de autores como Ruschman (2000); Dias (2002) e Gonçalves (2004) que apontam esse fator como um dos benefícios que o turismo pode trazer, quando planejado visando a sustentabilidade e a geração de emprego e renda.

Apesar da preocupação com a capacitação dos recursos humanos nos empreendimentos, não existia uma política efetiva para sanar essa preocupação. O entrevistado Mario (63) ao responder a mesma questão que os participantes acima, expõe: "Mas é óbvio! Meus funcionários são todos nativos, não tem ninguém de fora e também com formação. Devido a minha preocupação em relação a isso eu adquiri cursos em DVD. [...] Chamo as pessoas fico ali uma hora, duas horas mostrando". Outro participante que chamaremos de Felipe, é médico e tem uma pousada na Baía da Traição, nos afirma: "É um problema! A gente prioriza, só que não tem pessoas capacitadas." Esse fato vai de encontro à pesquisa de Menezes et. al. (2011) ao dizer que os funcionários dos empreendimentos hospitaleiros do litoral norte da Paraíba não obtinham capacitação suficiente.

A partir dos diálogos para identificar a natureza das intervenções nas práticas dos empreendimentos percebeu-se 0 anseio pela capacitação, motivando o desenvolvimento de minicursos. No entanto, observou-se que existe uma rotatividade acentuada de funcionários nos empreendimentos, além da inexistência de cursos de capacitação oferecidos para a comunidade. Os minicursos realizados foram, então, extensivos à participação de indivíduos da comunidade local como uma estratégia de incentivar a inclusão social. Santos (2000) alerta que vivemos, na atualidade, entre a tirania do dinheiro e da informação e que essa última não é universalizada, acarretando no processo de desigualdade. De modo que a periferia, dentro do sistema capitalista, torna-se cada vez mais marginalizada.

Sabendo da importância da qualificação dos recursos humanos para os meios de hospedagem e da carência de cursos profissionalizantes oferecidos à população da região, achamos importante documentar a participação de todos através de certificados. Os certificados foram gerados pela Universidade Federal do Rio Grande do Norte através de um projeto de extensão. A duração total dos minicursos foi de oito horas divididas em dois dias ou períodos, resultando em dois certificados, cada um de quatro horas/aula.

Mesmo sabendo que nosso objeto de estudo é a relação dos meios de hospedagem com a sustentabilidade ambiental, ao conhecer a realidade dos empreendimentos constatou-se a inexistência de conceitos básicos para a prestação de um serviço seguro e de qualidade. Questões simples e importantes,

Revbea, São Paulo, V. 13, № 2: 396-416, 2018. 
a exemplo da utilização de Equipamentos de Proteção Individual (EPI) para as pessoas que trabalham com a governança ou com qualquer outra função susceptível a acarretar acidentes, não foram vistos; ou de recepcionistas que não dominam as técnicas de atendimento e de check-in e check-out foram algumas das fragilidades percebidas.

De início, indagou-se sobre a possibilidade de apresentar uma proposta sustentável aos serviços oferecidos pelos empreendimentos, pois detectou-se que nem mesmo os serviços básicos apresentavam desempenho adequado. Esses fatores foram observados in loco durante a visitação. Sendo assim, foram propostos dois minicursos, sendo o primeiro intitulado "Introdução ao Turismo e às Práticas da Hospitalidade", e o segundo "Introdução ao Turismo Sustentável e Gestão Ambiental na Hospitalidade". Para elaboração do conteúdo das cartilhas utilizou-se, dentre outras referencias, a obra de Castelli. Castelli (2003) afirma que o sucesso na hotelaria está nos recursos humanos e, na opinião do mesmo, esse sucesso "pode se dar através da educação e do treinamento, ou seja, através do aporte do conhecimento, do desenvolvimento das habilidades, da formação de nos hábitos (atitudes) e da indicação das perspectivas para seu crescimento profissional' (CASTELLI, 2003, p. 34). Mesmo para abordar a temática ambiental, Dias (2003, p. 113) acrescenta que o turismo baseado em preceitos ecológicos, diferentemente do turismo tradicional, trata-se de iniciativa que demanda pouco investimento em infraestrutura e alto investimento em capacitação, conhecimento e informação.

Nos minicursos buscou-se expor aos participantes noções introdutórias do turismo e consequentemente da hotelaria. No primeiro momento foram expostos os conceitos do turismo, sua importância e como ele se desenvolve; os números que mostram a ascensão do turismo na atualidade, da geração de renda, do impacto econômico do turismo e da hotelaria no Brasil e no mundo. Além dessa parte introdutória, explanou-se sobre as técnicas nos serviços da hotelaria, fragmentação dos setores de um meio de hospedagem e suas funções; práticas da recepção, reservas/vendas e governança.

No segundo momento desenvolveu-se a temática ambiental, partindo dos problemas iniciados com a Revolução Industrial, passando pela contradição do nosso sistema econômico que prioriza o lucro frente à natureza; mostrando os efeitos de um desenvolvimento que não respeita o meio ambiente a partir da relação entra a produção industrial e os recursos naturais, e chegando aos conceitos de sustentabilidade e desenvolvimento sustentável.

Depois de expostos os problemas do nosso modelo de desenvolvimento, partimos para a importância da inserção da sustentabilidade no turismo, conceituando turismo sustentável e a importância de um planejamento turístico que leve em consideração a sustentabilidade local.

Finalizou-se o segundo minicurso apresentando a gestão ambiental na hotelaria, sua importância para a sobrevivência de um meio de hospedagem no mercado competitivo; mostrou-se técnicas e práticas que auxiliam na diminuição 
dos impactos provocados pelos meios de hospedagem e exemplos de hotéis que fazem uso dessas técnicas.

Ao ministrar os minicursos foi percebido que os participantes tinham um laço topofílico (TUAN, 2012) muito acentuado com o local. Ao expor a importância deles (nativos) no planejamento turístico do seu local e que eles não são e nem podem ser tidos como produtos (RUSHMAN, 2000), os mesmos se mostraram proativos em relação à conservação do seu local. Notou-se que a percepção deles sobre o turismo é muito digna, não o concebendo enquanto prática predatória, mas sim como uma forma de privilegiar e respeitar a natureza e a cultura local. Demonstraram conhecimento em relação aos impactos do turismo no seu ambiente local e os riscos que esse corre. Essa percepção, ainda que pouco declarada perante os órgãos públicos, e ainda que esse saber se limite a testemunhar os impactos do desenvolvimento, não invalida, enquanto saber, pois para Freire $(1987$, p. 68) "não há saber mais ou saber menos: há saberes diferentes".

O objetivo principal, ao final do minicurso, não foi apenas mostrar técnicas e enquadrar os participantes em uma perspectiva alienada à excelência de técnicas, visando à competitividade. Santos (2000) nos ensina que tal pensamento faz parte da "perversidade da globalização". Ao mostrar, por mais que de forma introdutória e superficial, a importância da sustentabilidade, vislumbrou-se que os participantes se tornem atores de mudança ou de resistência dos seus locais em busca da sustentabilidade. Gadotti (2011, p. 77) diz que "educar para a sustentabilidade implica mudar o sistema".

Sobre o desdobramento das ações levou-se em consideração a complexidade que envolve a sustentabilidade relacionando as temáticas interligadas, ou seja, buscou-se a transdisciplinaridade. Morin (1999, p. 18) diz que é preciso: "uma reorganização do saber na qual seriam ressuscitadas, de uma nova maneira, as noções trituradas pelo parcelamento disciplinar: o ser humano, a natureza, o cosmos e a própria realidade".

Os minicursos foram ministrados de forma individual em cada meio de hospedagem, por preferência de alguns proprietários, com exceção do município de Mataraca, onde foi realizado, de comum acordo entre os participantes da pesquisa, em um único dia e em um local comum a todos: na antiga sede da ONG Caranguejo Uçá (Ucides Cordatus), que hoje é um bar-café. No entanto, nesse último município a presença dos funcionários e proprietários dos meios de hospedagem foi muito pequena perante a presença majoritária dos moradores da cidade, demonstrando o envolvimento da população local como uma peculiaridade.

O município de Baía da Traição foi onde mais se encontrou empreendimentos dispostos a participar dos minicursos e, portanto, da pesquisa. Dentre os seis meios de hospedagem pesquisados, quatro participaram da ação, sendo que, no município de Lucena, de três empreendimentos participantes nenhum se propôs a participar desta ação; em Rio Tinto foi somente um entre 
dois empreendimentos participou; em Marcação o único participante também não se disponibilizou.

A realização dos minicursos foi entre os dias 16 de outubro e 30 de novembro de 2016. As datas foram marcadas a partir da disponibilidade de cada meio de hospedagem, ficando a escolha do dia sempre a critério destes. 0 convite aos participantes ocorreu em conformidade ética à Norma CNS 466/2012 que trata de pesquisas envolvendo seres humanos. Com o Termo de Consentimento Livre Esclarecido alertou-se aos convidados que o minicurso estaria à disposição deles podendo ser realizado em momento oportuno.

Ao todo foram quarenta e dois participantes, divididos entre funcionários e proprietários dos meios de hospedagem envolvidos nas ações, e moradores locais interessados nas temáticas e em se qualificar para o mercado de trabalho. A realização dessa ação pode ser considerada como de extrema importância tanto para os proprietários dos estabelecimentos quanto para os funcionários.

As dificuldades constatadas na frequência compreendiam fatores como o esquecimento da data; dificuldade de estabelecer e ou marcar o dia das aulas; indisponibilidade de alguns proprietários; preferência pela concentração dos cursos em um único dia, com sobrecarga e visível cansaço entre alguns integrantes; e credibilidade em relação aos motivos da ação.

\section{Cartilhas}

Os participantes da pesquisa sempre se mostraram muito preocupados em ter acesso maior à informação, tanto os proprietários quanto os funcionários. Alguns dos proprietários que já haviam utilizado ferramentas como vídeos/aulas solicitaram algum material para utilizar tanto como uma forma de reciclagem das temáticas expostas nos minicursos, como também para apresentar a novos colaboradores que chegam, uma vez que a hotelaria se constitui um ramo com uma rotatividade muito acentuada (FERREIRA, 2007) de funcionários. Essa característica requer treinamentos constantes, no entanto, não foi constatada essa estratégia entre os gestores pesquisados.

Mediante a solicitação de material técnico-educativo impresso por parte de alguns participantes foram propostas duas cartilhas. Para elaboração destas, buscou-se consultar os participantes para saber a natureza dos conteúdos considerados importantes para constar no material. Dentre os temas de maior interesse destacou-se a parte prática da hotelaria: questões relacionadas à recepção, governança, reservas etc. Assim, além de utilizarmos essas temáticas, sugerimos a adição da temática ambiental no turismo e na hotelaria. As cartilhas contemplaram os assuntos tratados nos minicursos. O conteúdo exposto foi dividido em dois momentos na intenção de favorecer a parte didática e a clareza dos assuntos. A cartilha pode ser considerada um material de educação informal. Bacelar et. al (2009) nos diz que, devido as especificidades do ambiente de trabalho em micro e pequenas empresas, a educação informal se mostra como um método com resultados mais expressivos que a formal.

revista brasileira educação ambiental 
Ao perguntar aos proprietários o grau de escolaridade de seus funcionários percebemos que era baixo. Assim seria importante que o material fosse compreensível e seu conteúdo acessível. Optou-se, então, pela elaboração de uma cartilha com teor objetivo e com o uso de imagens e conceitos de forma clara e concisa. Bacelar et. al. (2009) recomenda que as cartilhas sejam sucintas; com linguagem simples; adequadas ao nível técnico dos leitores e com introdução de termos técnicos.

Apesar da busca pela linguagem simples e acessível procurou-se manter o discurso de maneira que favorecesse a interdisciplinaridade da temática, ou seja, abordou-se a relação complexa entre turismo, hotelaria e meio ambiente e principalmente a importância dessa inter-relação.

A primeira cartilha destinada à parte prática da hospitalidade contém vários termos importantes para o cotidiano na operação dos serviços; mostrouse o passo a passo de um atendimento adequado para o check-in, check-out da recepção e reserva; abordou-se a governança, detalhando a importância de suas funções para um serviço de excelência; exibiu-se um check-list conforme apresentação de Marques (2004) que se configura como um dos mais adequados para a higienização de uma unidade habitacional. Além dessas questões tratou-se também, nessa primeira parte, do relacionamento com o cliente; do marketing; e de conceitos do turismo.

A segunda cartilha tratou das questões referentes aos conceitos de sustentabilidade, turismo sustentável e a importância de uma gestão ambiental nas operações dos meios de hospedagem; discorreu, ainda, sobre a importância na redução do consumo e consequentemente do lixo, o conceito dos 3 R's (reduzir, reutilizar e reciclar). Foram demonstradas ferramentas de auxílio na redução dos impactos na hotelaria na economia de energia, de água e dos resíduos sólidos.

Para a formulação da estrutura da cartilha buscou-se ajuda de uma designer gráfica que nos auxiliou criando todo o layout. Os materiais foram distribuídos em todos os meios de hospedagem que participaram da pesquisa, tanto os que se disponibilizaram a participar dos minicursos como os que não se disponibilizaram. A intenção foi que, mesmo não participando de uma atividade tão importante como as aulas, os pesquisados pudessem de alguma maneira obter informações importantes que os auxiliem na interpretação entre a gestão de um meio de hospedagem e a sustentabilidade. A oficina relacionada à cartilha 1 foi denominada Introdução às Práticas de Hospitalidade (Figura 1), conforme segue: 

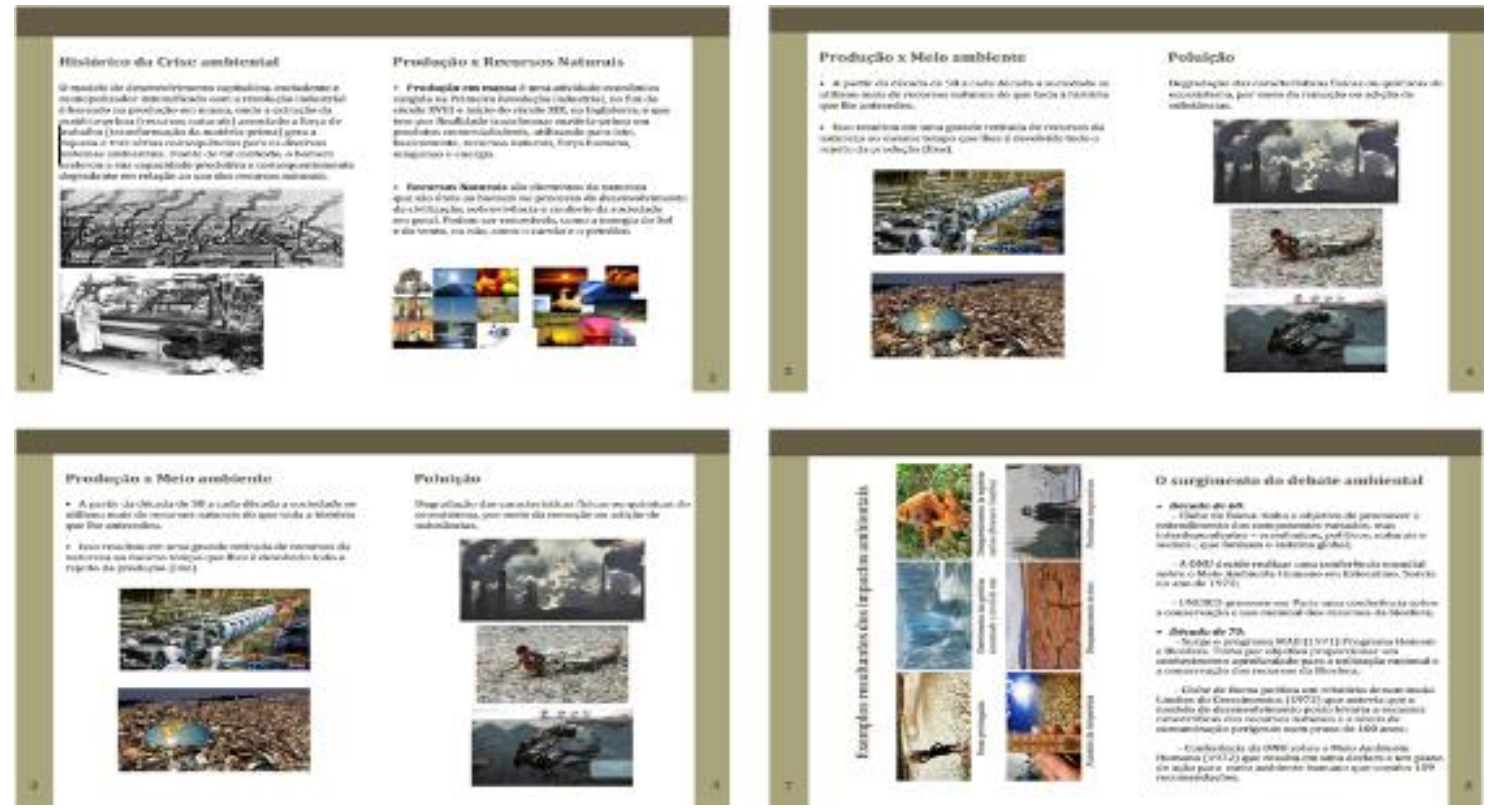

Figura 1: Cartilha 1. Introdução às práticas de hospitalidade em meios de hospedagem. Paraíba, 2016.

Fonte: Acervo pessoal dos autores.

Enquanto que a cartilha 2 foi chamada de Gestão Ambiental em meios de Hospedagem e abordou temas de acordo com as Figuras 2 e 3 :
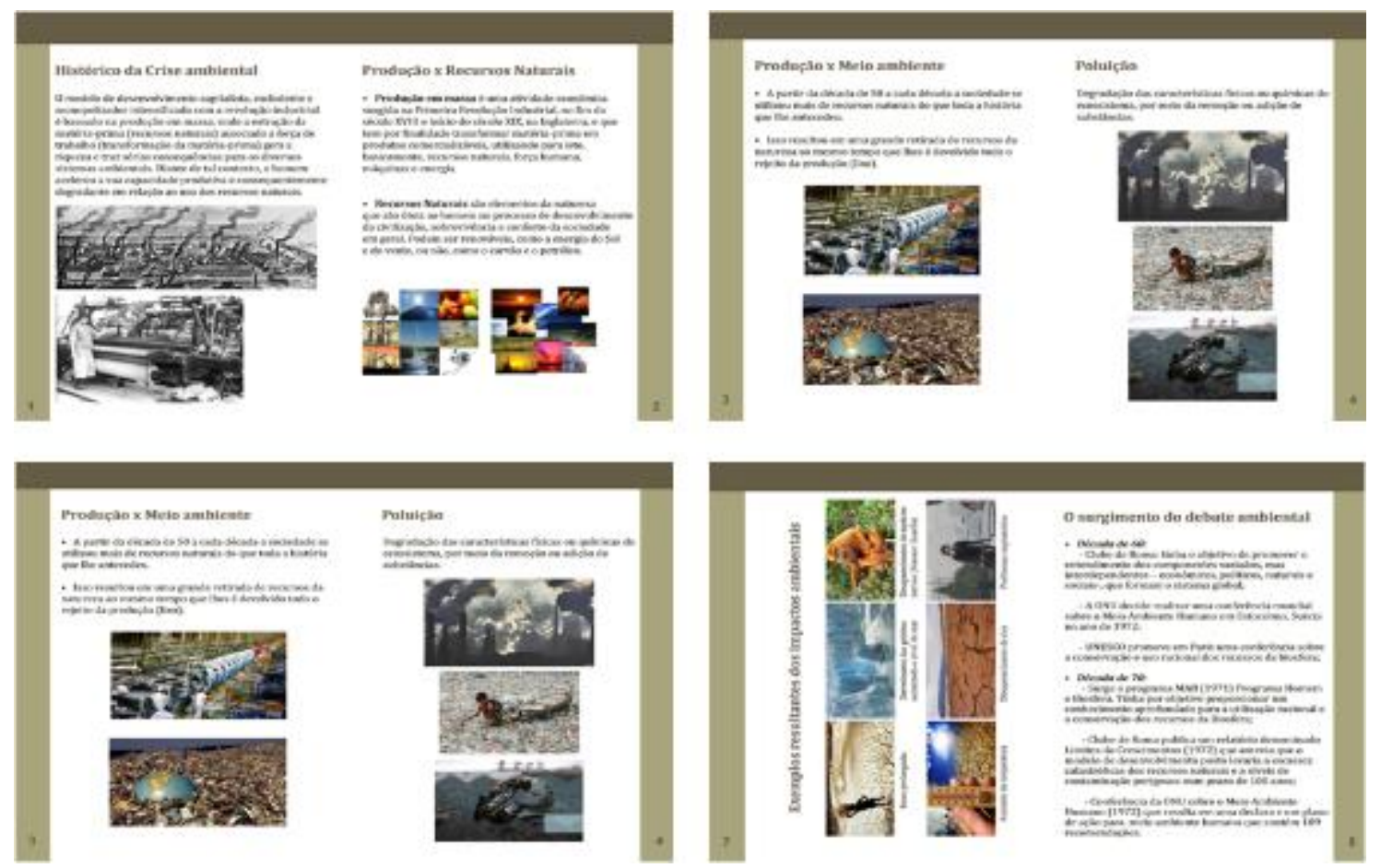

Figura 2: Cartilha 2. Histórico da crise ambiental. Paraíba, 2016.

Fonte: Acervo pessoal dos autores.

Revbea, São Paulo, V. 13, № 2: 396-416 2018.

revista brasileira

educação ambiental 

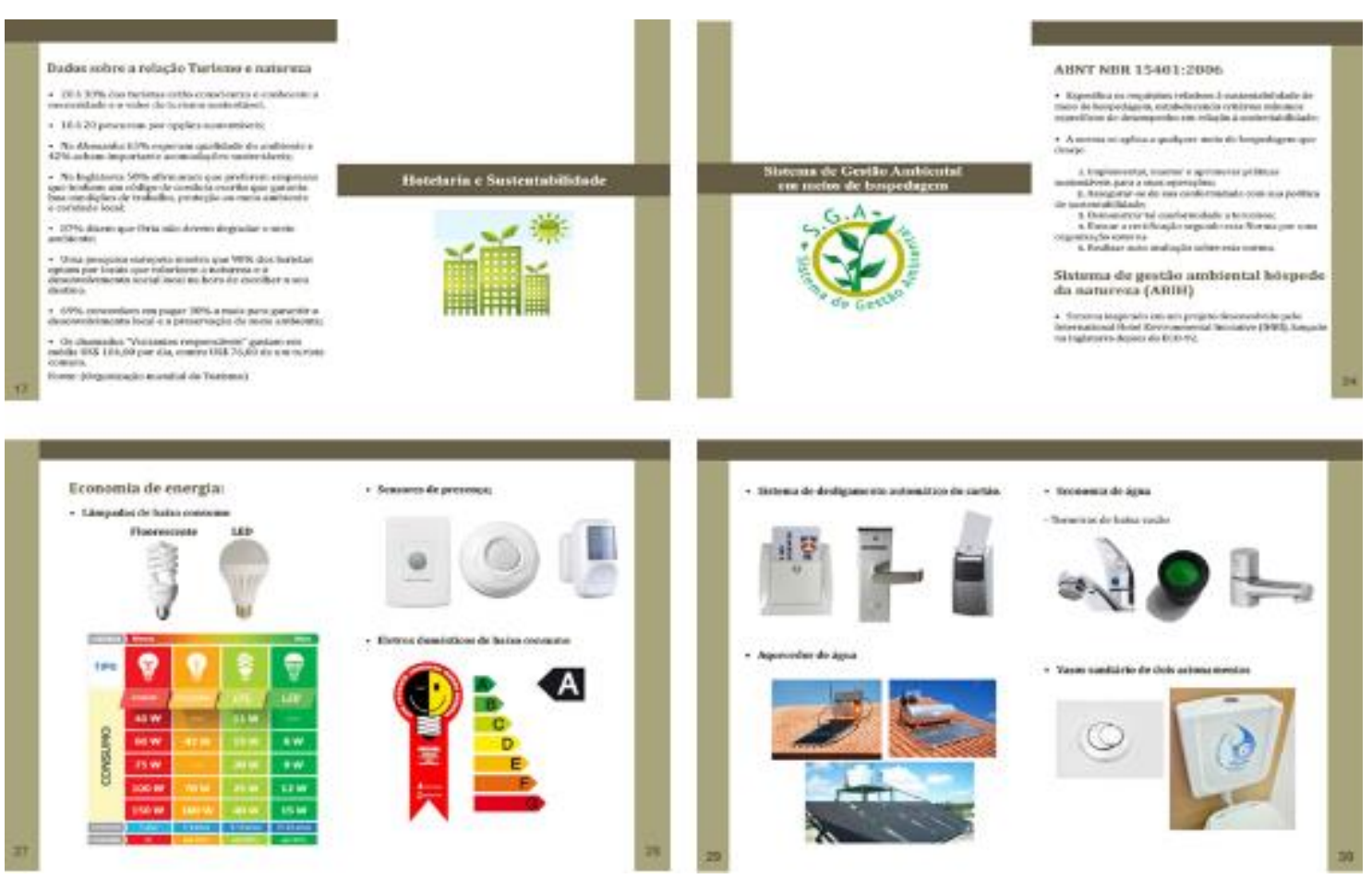

Figura 3: Cartilha 2. Relação Turismo, Hotelaria e Natureza. Paraíba, 2016.

\section{Apostilas}

Fonte: Acervo pessoal dos autores

A pesquisa-diagnóstico demonstrou que a gestão dos meios de hospedagem do litoral norte da Paraíba não se enquadra na perspectiva de uma gestão sustentável. Apesar de algumas práticas isoladas terem sido encontradas em determinados empreendimentos, em nenhum deles a questão ambiental recebeu a devida ênfase. Tal fenômeno é derivado de vários fatores: questões financeiras, estruturais e informacionais (foco das ações).

A última ação focou na gestão dos meios de hospedagem e foi elaborada em resposta à lacuna que ocorre entre o ideal de sustentabilidade e a gestão dos meios de hospedagem. Um dos aspectos mais importantes a ser abordado tratava-se diretamente da postura dos gestores em aderir a uma atitude mais responsável ambientalmente.

Sendo assim, sugerimos aos proprietários a entrega de um material elaborado através da parceria entre a Associação Brasileira de Normas Técnicas (ABNT) e o Serviço de Apoio às Micro e Pequenas Empresas (SEBRAE) intitulado Meios de Hospedagem: sistema de gestão da sustentabilidade. Esse material é um guia no auxílio aos meios de hospedagem que planejam a implementação do sistema de gestão ambiental como um todo ou apenas parcialmente, como forma de administrar seus impactos. O guia pode ser consultado de forma pontual para auxiliar no entendimento e permitir uma interpretação adequada de cada requisito da norma ABNT NBR 15401, não sendo necessária sua leitura na ordem do método de implementação apresentado (ABNT, 2012). 
O Brasil foi o primeiro país a desenvolver uma norma dedicada especialmente aos meios de hospedagem (ABNT, 2012). A norma da ABNT 15 401 tem como objetivo:

Especificar os requisitos relativos à sustentabilidade de meios de hospedagem, estabelecendo critérios mínimos específicos de desempenho em relação à sustentabilidade e permitindo a um empreendimento formular uma política e objetivos que levem em conta os requisitos legais e as informações referentes aos impactos ambientais, socioculturais e econômicos significativos (ABNT, 2006, p. 1).

Souza e Alvares (2014) afirmam que essa norma se destaca devido ao seu ineditismo e ao fato de se apresentar como uma norma específica para meios de hospedagem. Contudo, os autores também nos revela que poucos empreendimentos brasileiros buscam a certificação.

A proposta fornecida aos proprietários não foi a da certificação, devido, entre outras questões, à complexidade que envolve o processo de certificação ambiental. A nossa intenção foi a de aproximar os proprietários de materiais que possam auxiliar na gestão dos seus negócios. O documento apresentado é muito didático e teve uma boa aceitação como proposta.

Espera-se que esse material contribua com os proprietários e gestores dos empreendimentos pesquisados, tanto na adoção de práticas sustentáveis como de estratégias administrativas, mirando sempre a redução dos impactos socioambientais resultantes da configuração dos seus serviços, além de um desenvolvimento que inclua os povos que ali existem, seus costumes, sua cultura e suas histórias.

\section{Conclusão}

Concluiu-se que os meios de hospedagem do litoral norte da Paraíba se configuram majoritariamente como empreendimentos de pequeno porte cujo perfil é favorável ao desenvolvimento de um turismo sustentável e ou de base comunitária, que priorize o pequeno empresário e divirja dos empreendimentos que se utilizam de grandes áreas para a construção de suas instalações, a exemplo de grandes resorts.

Evidenciou-se a necessidade de apoio aos gestores e proprietários através da implementação de políticas públicas que incentive e monitore práticas sustentáveis em empreendimentos dessa natureza. São desejáveis ações de extensão conjuntas entre o público e o privado. Considerando a presença da Universidade Federal da Paraíba na região, poderiam ser concentrados esforços para a elaboração de projetos de extensão, com métodos e estratégias de gestão, para a conscientização da importância da preservação ambiental para o desenvolvimento de forma sustentável da região. 
Constatou-se que o litoral norte Paraibano configura-se como um novo "produto" turístico, detendo investimentos públicos com programas e incentivos ao turismo na região, contudo não representa os anseios da comunidade local. O projeto, cujo cerne se propõe a buscar a sustentabilidade, todavia não tem um planejamento estratégico de qualidade.

Outros estudos serão necessários para avaliar a aquisição de conhecimento através das ações implementadas e se houve alguma mudança de comportamento por parte dos empreendimentos participantes. Ações que estimulem a organização social para instrumentalizar reivindicações frente ao poder público são particularmente desejáveis.

Concluiu-se com a esperança de que a presente proposta traga benefícios à gestão dos meios de hospedagem do litoral norte da Paraíba. Que as reflexões expostas sobre a relação do turismo e da hotelaria com a natureza tenham sido apreendidas pelos participantes. Finalmente, espera-se contribuir para a conservação dessa região que deve ser apreciada, mas nunca explorada.

\section{Agradecimentos}

A Coordenação de Aperfeiçoamento de Pessoal de Nível Superior (CAPES), pelo apoio financeiro à pesquisa através de bolsa de estudos;

\section{Referências}

ASSOCIAÇÃO BRASILEIRA DE NORMAS TÉCNICAS (ABNT)/SEBRAE. Meios de hospedagem: sistema de gestão da sustentabilidade. Rio de Janeiro: ABNT/SEBRAE, 2012.

BACELAR, M F.; PINHEIRO T.S.M.; LEAL, M.F.; PAZ, Y.M.; LIMA, A.S.T.; ALBUQUERQUE, C.G. Metodologia para elaboração de cartilhas em projetos de educação ambiental em micro e pequenas empresas. Recife: Jepex, 2009.

BARBOSA-SEGUNDO, I.D. Análise das Condições de Salubridade Ambiental dos Municípios com Potencial Turístico do Litoral Norte Paraibano. João Pessoa. Dissertação (Mestrado em Desenvolvimento e Meio Ambiente) - UFPB, 2015.

BOFF, L. Sustentabilidade: 0 que é - O que não é. Petrópolis:: Vozes, 2014.

BOHDANOWICZ, P. Europan Hoteleirs' Enviroment Attitudes. Cornell And Restaurant Administration Quarterly, Thousand Oaks, v. 46, n. 2, p. 188-204, 2005.

BUARQUE, S.C. Metodologia de Planejamento do desenvolvimento local e Municipal Sustentável. Projeto de Cooperação Técnica INCRA/IICA-PCT. Brasília: INCRA/IICA; 1999.

CAMARGO, A.M.B. Sustentabilidade: dimensões e desafios. Campinas: Papirus, 2003. 
CASTELLI, G. Administração Hoteleira. Caxias do Sul: EDUSC, 2003.

CESAR, P.H.C. Avaliação de práticas de gestão ambiental em meios de hospedagem situados no litoral norte do estado da Paraíba. Mamanguape. Trabalho de Conclusão de Curso (Graduação) - Curso Superior de Hotelaria.UFPB, 2013.

CHIAZZOTTI. A. Pesquisa Qualitativa em Ciências Sociais. Petrópolis: Vozes, 2006.

CORIOLANO, L N.M.T. O turismo comunitário no nordeste brasileiro. In: Turismo de Base Comunitária: Diversidade de olhares e experiências brasileiras. Rio de Janeiro: Letra e imagem; 2009.

CORIOLANO, L.N.M.T.; VASCONCELOS, F.P. 0 turismo e a relação sociedade-natureza: realidade, conflitos e resistências. Fortaleza: EDUECE, 2014.

CORIOLANO, L.N.M.T. Ecoturismo e contribuições ao desenvolvimento sustentável em comunidades - Ceará - Brasil. Revista Geográfica da América Central, número especial EGAL, p. 1-19, 2011.

DIAS, R. Gestão ambiental: responsabilidade social e sustentabilidade. 2 ed. São Paulo: Atlas, 2011.

DIAS, R. Turismo Sustentável e Meio Ambiente. São Paulo: Atlas, 2003.

DIEGUES, A.C. O mito da Natureza Intocada. São Paulo: HUCITEC, 2001.

FIGUEIRA, V.; DIAS, R. A Responsabilidade Social no Turismo. Lisboa: Escolar Editora, 2011.

FREIRE, P. Pedagogia do oprimido. 17 ed. Rio de Janeiro: Paz e Terra, 1987. GADOTTI, M. Educar para a sustentabilidade: uma contribuição á Década da educação para o Desenvolvimento Sustentável. São Paulo: Editora e Livraria Instituto Paulo Freire, 2011.

GONÇALVES, L.C. Gestão ambiental em meios de hospedagem. São Paulo: ALEPH, 2004.

GRIMM; I.J.; SAMPAIO, C A.C. Turismo de base comunitária: convivencialidade e conservação ambiental. Revista Brasileira de Ciências Ambientais, São Paulo, n. 19, p. 57-68, 2011.

HAGUETTE, T.M.F. Metodologias qualitativas na sociologia. Petrópolis: Vozes, 2007.

INSTITUTO CHICO MENDES DE CONSERVAÇÃO DA BIODIVERSIDADE (ICMBio) -. Plano de Manejo da Área de Proteção Ambiental da Barra do Rio Mamanguape e da Ária de Relevante Interesse Ecológico de Manguezais da Foz do Rio Mamanguape. Brasília: ICMBio, 2014. 
LEFF, E. Saber Ambiental: Sustentabilidade, Racionalidade, Complexidade, poder. Petrópolis: Vozes, 2011.

MARQUES, J.A. Introdução à Hotelaria. Bauru: EDUSC, 2003.

MENEZES, P.D.L.; BAUDUINO, B.C.; BAUDUINO, J.C.; BRANDÃO, J.M.F. Gestão Hoteleira no litoral norte da Paraíba: estrutura e funcionamento. Qualitas Revista Eletrônica, Campina Grande, v. 1, n. 1, p. 1-18, 2001.

MORIN. E. O método: a natureza da natureza. Tradução por Maria Gabriela de Bragança. Portugal: Publicações Europa-América; 1977.

MORIN. E. Complexidade e Transdisciplinaridade: a reforma da universidade e do ensino fundamental. Natal: EDUFRN, 1999.

NADER. R.T. Crise socioambiental: estado \& sociedade civil no Brasil (19821998). São Paulo: Annablume/FAPESP; 2002.

PEARSON, Academia. Gestão Ambiental. Campinas: Pearson Brasil, 2011.

PIZZOL, K.M.S. A. o processo de estruturação urbana no litoral norte da Paraíba e as intervenções no meio ambiente: o caso de Lucena - PB. Revista Caminhos de Geografia, Uberlândia, v. 6, n. 9, p. 80-9, 2006.

PORTO-GONÇALVES. C.W. A globalização da Natureza e a Natureza da Globalização. Rio Janeiro: Civilização Brasileira, 2015.

PORTO-GONÇALVES. C.W. O desafio ambiental: Os porquês da Desordem Mundial. Mestres Explicam a Globalização $3^{\circ}$ edição. Rio de Janeiro: Record, 2012.

POUPART, J. A pesquisa qualitativa: enfoques epistemológicos e metodológicos. Tradução de Ana Cristina Nasser. Petrópolis: Vozes, 2008.

RUSCHMAN, D.V.M. Turismo e Planejamento Sustentável. Campinas: Papirus, 2000.

SACHS, I. Caminhos para o Desenvolvimento Sustentável. Rio de Janeiro: Garamond Universitária, 2009.

SANTOS, M. Por uma outra globalização: do pensamento único a consciência universal. Rio de Janeiro: Record, 2000.

SEIFFERT, M.E.B. Gestão Ambiental: instrumentos, esferas de ação e educação ambiental. São Paulo: Atlas, 2009.

SOUZA, C.A.; ALVARES, R.C.S. Certificação sustentável em meio de hospedagem - Caso da Certificação Ambiental NBR 15401 no Brasil. Revista Rosa dos Ventos - Turismo e Hospitalidade, Caxias do Sul, v. 6. n.4, p. 53145, 2014.

THIOLLENT, M. Metodologia da pesquisa-ação. São Paulo: Cortez, 1986.

VEIGA, J.E. Meio Ambiente e Desenvolvimento. São Paulo: SENAC, 2012.

VEIGA, J.E. O âmago da sustentabilidade. Revistas de Estudos Avançados, São Paulo, v. 28, n. 82, p. 7-23, 2014.

Revbea, São Paulo, V. 13, № 2: 396-416, 2018. 